\title{
A Novel Tool for the Determination of Tropopause Heights by Using GNSS Radio Occultation Data
}

\author{
Francesco Vespe ${ }^{1}$, Rosa Pacione ${ }^{2}$, Elisa Rosciano ${ }^{1}$ \\ ${ }^{1}$ Centro di Geodesia Spaziale, Agenzia Spaziale Italiana, Matera, Italy \\ ${ }^{2}$ Centro di Geodesia Spaziale, e-GEOS , Matera, Italy \\ Email: francesco.vespe@asi.it,Francesco.vespe@asi.it
}

How to cite this paper: Vespe, F., Pacione, R. and Rosciano, E. (2017) A Novel Tool for the Determination of Tropopause Heights by Using GNSS Radio Occultation Data. Atmospheric and Climate Sciences, 7, 301313.

http://dx.doi.org/10.4236/acs.2017.73022

Received: April 11, 2017

Accepted: July 10, 2017

Published: July 13, 2017

Copyright $\odot 2017$ by authors and Scientific Research Publishing Inc. This work is licensed under the Creative Commons Attribution International License (CC BY 4.0). http://creativecommons.org/licenses/by/4.0/

\section{Open Access}

\begin{abstract}
The tropopause is a transitional layer between the troposphere and the stratosphere. The exchange of chemical constituents of the atmosphere (namely masses of air, water vapor, trace gases etc.) and energy between the troposphere and the stratosphere occurs through this layer. We suppose that just exchanges that are taking place at the tropopause heights are strongly influenced by the Global Change forcing. For this reason it is particularly urgent to accumulate temporal data the most accurate possible and with a certain continuity series to understand comprehensively what is happening to our climate. It is well known that Radio Occultation technique applied using Global Navigations Satellite Systems (GNSS-RO) is a powerful tool to detect the tropopause heights. It can be done working on the level 2 data provided by GNSS-RO payload: i.e. atmospheric profiles of pressure and temperature. We propose to measure tropopause using GNSS-RO level 1 data; i.e. the bending angles (BA) of the GNSS signal through the atmosphere. We fit the BA profiles applying in the integral relationship of $\mathrm{BA}$ as refractivity profile of background the Hopfield dry model of atmosphere which depends on the fourth degree of the height above the Earth. Through the layers in which tropopause is contained, the residuals between the background model and the observed BA have an anomalous trend. The residuals in this zone form anomalous non-gaussian bumps that we have exploited just to determine the relevant parameters of the tropopause. Such bumps are due to the wrong theoretical assumption made by Hopfield for the re-construction of the dry refractivity that the temperature lapse rate of the atmosphere is constant. But we know that the definition of tropopause according the World Meteorological Organization (WMO) is just the height where a sudden change of the temperature lapse rate usually occurs. Thus in the present work we have determined tropopause heights with new algorithms which exploit the bumps occurring
\end{abstract}


along the BA profiles achieved by GNSS-RO. We have used the huge amount of data provided by several space missions devoted to GNSS-RO (namely COSMIC, METOP, etc.) for tuning the algorithms, performed a validation and provided a robust statistical soundness. The same GNSS-RO observations are helpful also to reconstruct the Mapping Function commonly applied in geodetic applications. Global mapping functions built with GNSS-RO and their evolution in time can be an interesting parameter helpful for climate investigations as well.

\section{Keywords}

Tropopause, Radio Occultation, Global Navigation Satellite Systems, Atmosphere Physics

\section{Introduction}

In 1996, the Intergovernmental Panel on Climate Change (IPCC) [1] concluded that "the balance of evidence suggests a discernible human influence on global climate." The latest IPCC reports (hereafter AR5) [2] confirm this conclusion: "Warming of the climate system is unequivocal, and since the 1950s, many of the observed changes are unprecedented over decades to millennia. The atmosphere and ocean have warmed, the amounts of snow and ice have diminished, sea level has risen, and the concentrations of greenhouse gases have increased." These statements summarize the results of the investigation in a broad spectrum of fields. The helpful strategy is the construction of possible observational climate "fingerprints" which can sense modifications due to anthropogenic causes assessed after an extensive statistical analysis of their interactions with climate observations. Thus further parameters and "fingerprints", other than the classical study of surface temperature and zonal-mean temperature profiles, can help us to single out human influence on global climate change.

It is well known as signals of Global Change are given not only by Earth's temperatures but also by a wide variety of other parameters such as the integrated heat content [3], Northern Hemisphere sea ice extent [4] or to other kind of temperature-related indices: gradient of temperatures between land and ocean, low and high latitudes or North/South Hemisphere [5]. Other kind of fingerprints can be considered the "Greenhouse Climate Response Index [6] and the Common-Sense Climate Index [7] which take into account the coupling of temperature and moisture. This just to strengthen that a stack of a lot and different kind of relevant climatic signals, not limited to the temperature only, can flag coherently anthropogenic origin of Global Change [8]. Examples of statistical studies using alternative detection variables include analyses of changes in integrated ocean heat content [3] and Northern Hemisphere sea ice extent [4]. There has also been interest in various temperature-related indices, such as the temperature contrast between land and ocean, low and high latitudes, and the Northern and Southern Hemispheres [5]. Other indices, such as the "Green- 
house Climate Response Index" [6] and the "Common-Sense Climate Index" [7], simultaneously consider changes in temperature and moisture.

One of the temperature-free variables that has not been still fully exploited for climate change investigations is height of the tropopause [8] [9] [10]. The tropopause is the transition zone between the turbulently mixed troposphere and the more stable laminar layers of stratosphere [11]. This transition is also detectable by changes in lapse rate and the chemical composition of the atmosphere [9]. Because the location of the tropopause can be defined in a wide variety of ways, according to dynamic, thermal, and chemical properties of the atmosphere [8] [11], it would be more precise to define the tropopause as a thick layer of the atmosphere where the transition between the troposphere and stratosphere occurs. Stratospheric $\mathrm{H}_{2} \mathrm{O}$ vapour has an important role in the Earth's radiative balance and in stratospheric chemistry [2]. Increased stratospheric $\mathrm{H}_{2} \mathrm{O}$ vapour causes the troposphere to warm, the stratosphere to cool [2] [10] [11] and causes increased rates of stratospheric $\mathrm{O}_{3}$ loss [12]. Water vapour penetrates into the stratosphere through the cold tropical tropopause [2].

While moisture-rich air masses are transported through this region, most water vapour condenses resulting in extremely dry lower stratospheric air. Thus $\mathrm{H}_{2} \mathrm{O}$ abundance varies seasonally as well as the tropopause temperature does. Other possible causes can be a direct injection of $\mathrm{H}_{2} \mathrm{O}$ vapour due to overshooting convection mechanism as well as oxidation of methane within the stratosphere [12]. In the 5th IPCC report [2] is stated that "stratospheric $\mathrm{H}_{2} \mathrm{O}$ vapour showed significant long-term variability and an upward trend over the last half of the 20th century, but no net increase since 1996". In fact, the latest observations confirm inter-annual variations but not significant secular trends since 1996. The minimum temperature that marks the tropopause, wringing water out of the tropospheric air; thus any air reaching the stratosphere from below contains very little water vapour. The vertical temperature structure in the vicinity of the tropopause controls static stability and, therefore, determines where and how deeply air will penetrate into stratosphere from below.

In the last decades the structure of global tropopause has been studied mainly with radiosonde observations (RAOB) and reanalysis data from Numerical Weather Prediction (NWP) models provided by the European Centre for Medium Range Weather Forecasts (ECMWF) and the National Centers for Environmental Prediction (NCEP). The tropopause reacts to other factors as well: variations in solar radiation, atmospheric angular momentum, stratospheric ozone and, last but not least, to the explosive volcanic eruptions. The observations have identified decadal-timescale changes in tropopause height as explained in [13]. The evidence is that an increase in the height of the tropopause over the last several decades or longer, confirmed both by the ground observations in the tropics [8], or in tropical averages from reanalysis [14]. The coupling of such tropopause low frequency variations with changes in distribution of ozone through the stratosphere, confirms the reliability of such detected evidences [15]. The annual and inter-annual variations in the altitude of the tropi- 
cal tropopause are correlated with atmospheric angular momentum [9] [15]. So it has been widely demonstrated by more authors [10] [16] [17] that changes in the altitude of the tropopause caused by cooling in the stratosphere and warming in the troposphere [18] may be a sensitive indicator of anthropogenic climate change.

Studies since the 5th IPCC report [2] confirm the increase in tropopause height [19]. For tropical tropopause temperatures, studies based on radiosonde data and reanalyses partly support a cooling between the 1990s and the early 2000s [20] [21], but uncertainties in long-term trends of the tropical cold-point tropopause temperature from radiosondes [19] [20] and reanalyses [21] are large and confidence is therefore low [2].

In the last decade a huge number of GNSS RO data have opened very promising perspectives for a more refined monitoring of tropopause heights which, for all the above considerations done, revealed to be a powerful fingerprint for climate investigations. GNSS RO indeed have been widely demonstrated the capability to retrieve the temperature and the height of the tropopause within an error of $1 \mathrm{~K}$ and few hundreds of meters respectively as predicted in [22]. The huge amount of GNSS RO data mainly coming from the COSMIC space mission fully devoted to GNSS RO [23], has allowed to perform detailed investigation on the behavior of tropopause. At this purpose a special mention deserves the work done [24] in which a time series of RO data 37 months long has been processed in order to determine the time evolution of tropopause. The results of tropopause heights analysis performed by the authors [24] are reported in Table 1.

In the period from 2006 Sept. to 2009-Sept the variation of tropopause heights increased over the North polar area and in the equatorial bulge. The average trend in the equatorial bulge is of $1.4 \mathrm{~m} / \mathrm{yr}$ but in the restricted zonal $12 \mathrm{~N}-12 \mathrm{~S}$ its value is at a level of $2.2 \mathrm{~m} / \mathrm{yr}$. These observations performed with RO data confirm the trend experienced since 1978 about the rising of the tropopause cold point level by $20 \mathrm{~m}$ per decade, cooling by $0.5 \mathrm{~K}$ per decade, and decrease in pressure by $0.5 \mathrm{hPa}$ per decade through the equatorial bulge.

After having provided a wide and deep frame of how tropopause can be considered a key parameter for climate investigation, in the first section of the present work we will describe how currently the tropopause heights are determined. It will explain in particular the method to determine the Radio Tropopause by GNSS-RO as proposed in [25]. In the second part we will describe the novel

Table 1. The table reports the results achieved in [24]. We plan to prolong the analysis up to 6 years at least applying our algorithms for the detection of tropopause heights.

\begin{tabular}{ccc}
\hline Global Trend & $0.1 \mathrm{~m} / \mathrm{yr}$ & Increasing! \\
\hline $60 \mathrm{~N}-90 \mathrm{~N}$ & $11.1 \mathrm{~m} / \mathrm{yr}$ & \\
$24 \mathrm{~N}-60 \mathrm{~N}$ & $-3.1 \mathrm{~m} / \mathrm{yr}$ & \\
$18 \mathrm{~N}-18 \mathrm{~S}$ & $1.4 \mathrm{~m} / \mathrm{yr}$ & $2.2 \mathrm{~m} / \mathrm{yr}(12 \mathrm{~N}-12 \mathrm{~S})$ \\
$24 \mathrm{~S}-60 \mathrm{~S}$ & $-0.8 \mathrm{~m} / \mathrm{yr}$ & \\
$60 \mathrm{~S}-90 \mathrm{~S}$ & $-2.5 \mathrm{~m} / \mathrm{yr}$ & \\
\hline
\end{tabular}


algorithm we propose to determine the tropopause by GNSS-RO. Afterward we will show the results of validation performed.

In the 4th section we will propose a new possible key parameter, suitable to perform climate investigations: i.e. the Mapping Function built with GNSS-RO observations. Finally some conclusions and remarks will be drawn.

\section{How the Tropopause Is Determined}

The World Meteorological Organization (WMO) in 1957 provided a definition of MTs based on lapse rate tropopause (LRT), which until now is the only available way to detect MTs: "The lowest level at which the lapse rate decreases to 2 $\mathrm{C} / \mathrm{km}$ or less, provided that the average lapse rate between this level and all higher levels within $2 \mathrm{~km}$ does not exceed $2 \mathrm{C} / \mathrm{km}$." Using this definition and realizing the importance of the tropopause structure for climate investigations as extensively explained before, many investigators have studied the LRT using GNSS RO measurements [24] [25]. It was realized anyway that in the tropics, the cold point (CPT) is well marked in the temperature profile, and is more meaningful and relevant than the LRT. Thus in [25] it was proposed a method to identify the CPT exploiting the bending angles profiles (hereafter BA) of GNSSRO observations. Looking at Equation (1)

$$
\frac{\mathrm{d} \alpha}{\mathrm{d} h}=\tan (\Phi) \frac{77.6}{10^{6}} \frac{1}{T}\left[\frac{\mathrm{d} P}{\mathrm{~d} h}-\left(\frac{P}{T}\right) \frac{\mathrm{d} T}{\mathrm{~d} h}\right]
$$

where $\alpha$ is the BA, $P$ is the atmospheric pressure in mbar, $T$ is the temperature in $\mathrm{K}, h$ is the altitude in $\mathrm{km}$, and $\Phi$ is the angle between radio ray path and the radial direction. The variation in $\tan \Phi$ with altitude in the range $1 \mathrm{~km}$ to 20 $\mathrm{km}$ is approximately $0.095 \%$ and can be neglected. In the atmosphere, the first term in the parenthesis of the right hand side in Equation (1) is always negative and can be taken to vary smoothly with altitude [25]. On the other hand, the second term changes its sign from positive to negative from troposphere to stratosphere as $\mathrm{d} T / \mathrm{d} h$ changes sign from negative to positive with an abrupt change at the tropopause as $P$ is a smooth function of altitude [25]. Thus, any change in temperature gradient will be reflected in corresponding change in $\alpha$. At the tropopause, as the temperature gradient tends to zero, $\mathrm{d} a / \mathrm{d} h(=\alpha)$ reaches a peak followed by a sharp decrease as the temperature gradient turns positive [25].

\section{How Do We Determine the Tropopause}

We propose the BPV approach to retrieve humidity profile from GNSS RO observations without using external information [26] [27].

In the first step we adopt the Hopfield dry atmosphere refractivity model [28] (hereafter Hf] to fit the bending angles from the outer troposphere layers; i.e. where $h T \leq 250 \mathrm{~K}$, up to the stratopause. We guess indeed that through these layers the humidity content is negligible and the hydrostatic dry model of atmosphere work quite well. We outline that GNSS RO data are more reliable just in these layers. 


$$
\left\|\gamma_{o b s}(a)+2 \int_{r_{e}+h_{\perp}}^{r_{e}+h_{\max }} \frac{\mathrm{d}}{\mathrm{d} r}\left[\ln \left[n_{d r y}\left(r, P_{0}, T_{0}\right)\right]\right] * \frac{a}{\sqrt{n_{d r y}^{2}\left(r, P_{0}, T_{0}\right) r^{2}-a^{2}}} \mathrm{~d} r\right\|^{2}
$$

The parameters of Hf, surface pressure and temperature $P_{0}$ and $T_{0}$, are estimated by a Levenberg-Marquardt non-linear fit applied to the cost function as written in Equation (2).

where $\gamma_{o b s}$ are the observed bending angles, $h_{\perp}$ is the tangent point and $r_{E}$ is the Earth radius, $h_{\max }$ is the upper bound of ray tracing integration (namely stratopause) $a$ is the impact parameter.

$$
n_{d r y}\left(h(r), P_{0}, T_{0}\right)=1+10^{-6} N_{d r y, 0}\left[\frac{h_{d r y}-h}{h_{d r y}}\right]^{4} \text { where } N_{d r y, 0} \text { is the ground dry re- }
$$

fractivity $N_{d r y, 0}=a_{1} \frac{P_{d r y, 0}}{T_{0}}$ and $h_{d r y}$ is the Hf stratopause height [30]

$$
h_{d r y}=40136+148.72 \cdot\left(T_{0}-273.16\right)
$$

In the second step, from the estimated parameters $T_{0}$ and $P_{0}$, the dry BA is computed down to the ground by applying the dry Hf model. In Figure 2 the measured and dry BA are compared for selected sites [27]. Just looking at Figure 2 it can be observed the existence of a bump of the observed BA $(\Delta \gamma)$ (dark grey) with respect the dry Hf model (light grey), just at heights where we expect tropopause layer(s). In Figure 1 are reported indeed two plot for two different sites: the first in the equatorial zone; the II at mid latitudes. The bumps occur just at different heights. Through the layers selected to perform the fit of Hf parameters the behaviour of atmosphere fulfills the law of hydrostatic equilibrium but not at the tropopause. Let us briefly describe the Hf model. The model is theoretically based on an atmosphere with constant lapse rate of temperature. It treats the "dry" and "wet" component of refractivity separately and represents each as a fourth-degree function of height above the geoid (bi-quartic relationship). Thus the ripples we have through the tropopause layers are due to the (wrong) theoretic assumption of Hf that the lapse rate of temperature is constant. This is not the case. So the ripples are due to the inversion of temperature gradient which traps the humidity preventing it overflows in the stratosphere anymore. The rippling is evident in every $\mathrm{RO} \mathrm{BA} /$ refractivity profile fitted by $\mathrm{Hf}$ and it occurs at heights strongly correlated to the latitudes of the $\mathrm{RO}$ events. The ripples vanish when we adopt more refined models as shown [29]. Why there are strong reasonable grounds to believe that such ripples could be related to tropopause. Thus we have extracted 4 different parameters to determine the tropopause based just on the residuals between the observed BA and their fit with $\mathrm{Hf}$ model. $H_{\text {ave }}=\langle h * r e s \alpha / r e s \alpha\rangle$ is the average height of the layers where positive bumps occur (red square in Figure 2); $H_{\max }$ where we have the maximum value of the residuals (blue square); $H_{0}$ where the residuals start to be negative soon after $H_{\max }$ (green square); $H_{\min }$ where the residual is minimum (gray square). Figure 2 shows where the four proposed gauges place the tropopause. 


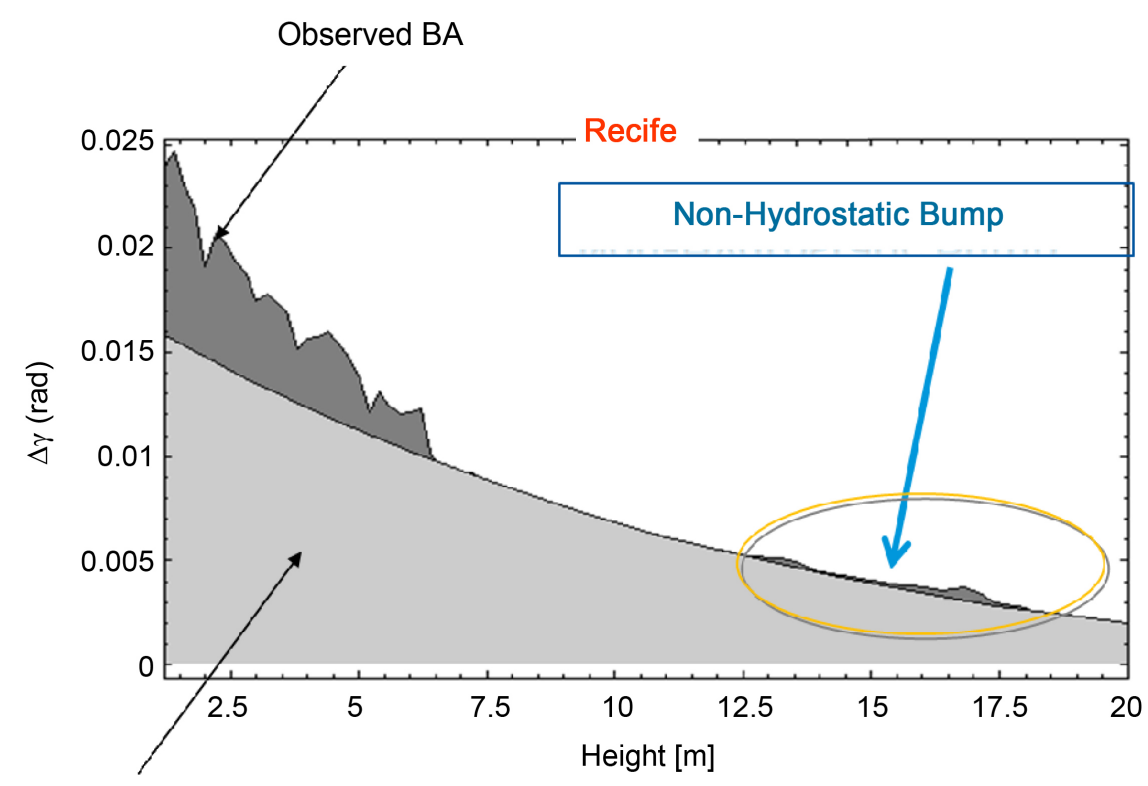

Background dry BA function

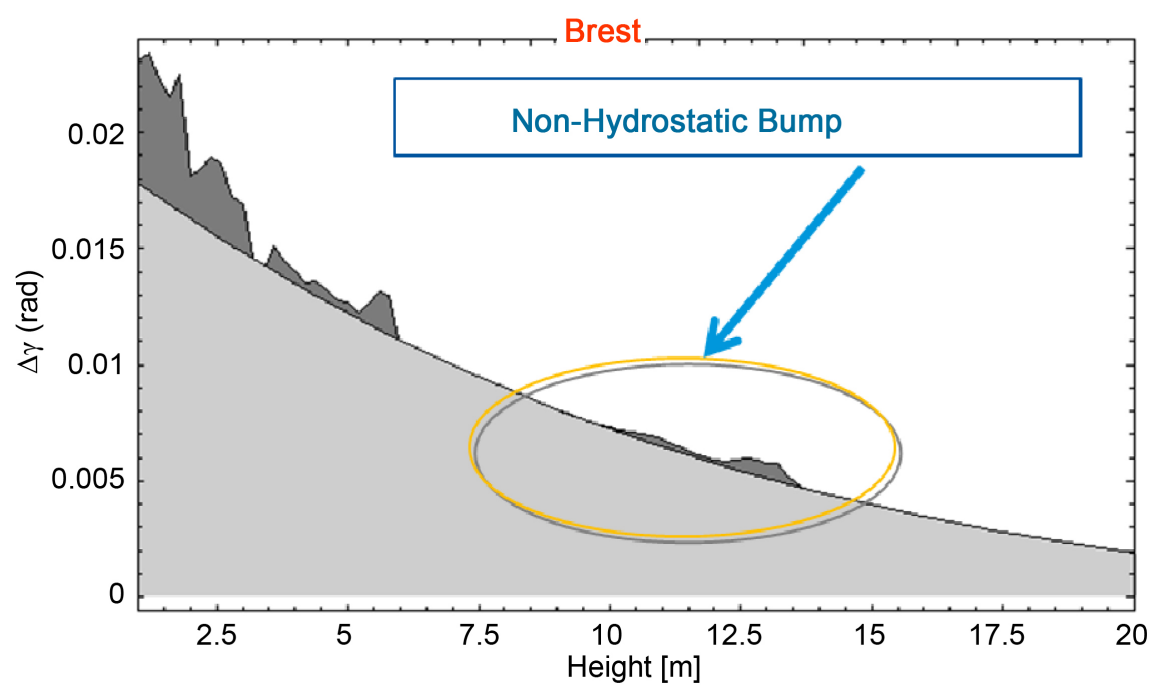

Figure 1. Plots of bending angles. Dark grey plot represents the observed BA; while light grey is due to the dry part of atmosphere as computed by Hf model. The first (RECIFE) regards an equatorial site; while the second one (BREST) is retrieved at the mid-latitudes.

\section{Results of Validation}

We have performed a validation of the proposed tropopause gauges using both GNSS RO and Radiosondes observations (RAOB). In particular we have computed in turn the CPT $\left(h_{C P T}\right)$ and LRT $\left(h_{L R T}\right)$ with GNSS-RO and the same parameters with RAOB $\left(h_{C P T-R A O B}, h_{L R T-R A O B}\right)$. In addition we have computed the Radio Tropopause $\left(h_{R T}\right)$ applying its definition just as conceived in [25]. For the activity of validation we have selected more than 2000 of GNSS-RO profiles coming from COSMIC [23] and METOP [30] missions. COSMIC is a joint Taiwan-USA/UCAR mission which consists of 6 satellites fully devoted to GNSSRO. 


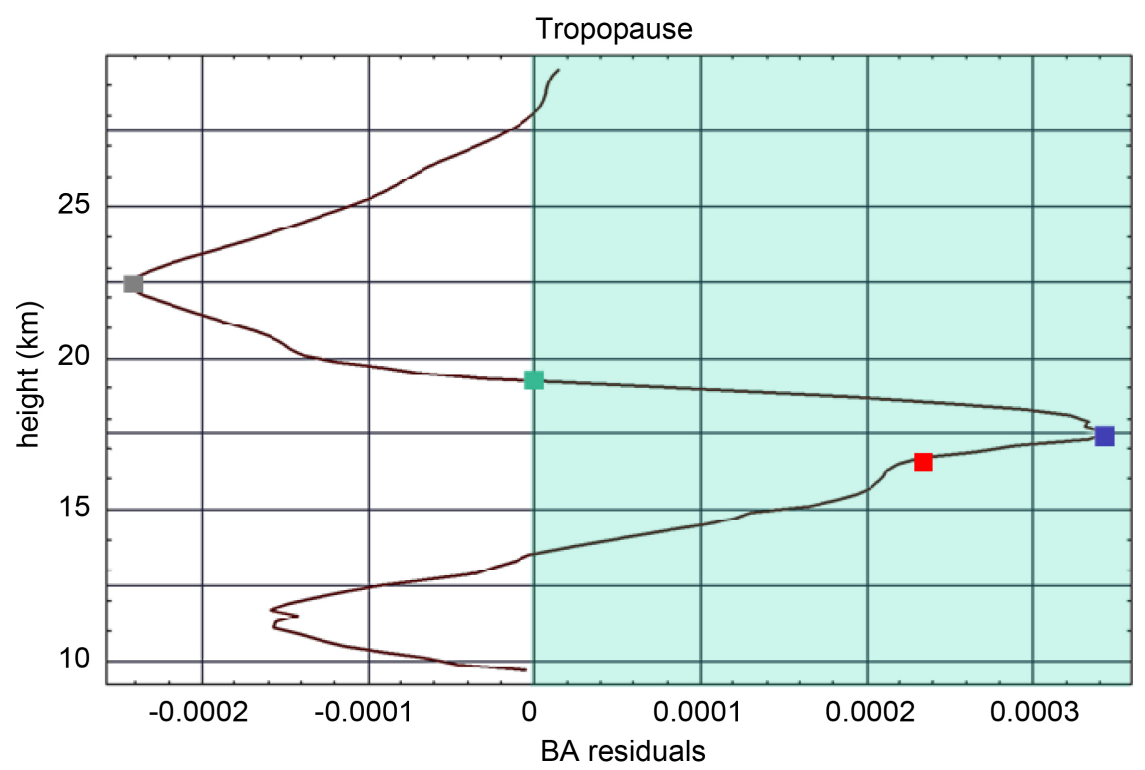

Figure 2. The figure shows the behaviour of the residuals between the observed and the Hf dry bending angles ( $\mathrm{rad}$ ) through the atmosphere layers where we expect to detect the tropopause heights (see circles in Figure 1). Red square shows the height where we can find $H_{a v e}$ blue where $H_{\max }$ green is for $H_{0}$ and grey square is for $H_{\text {min }}$. The behaviour of the residuals as shown in figure is common to almost the GNSS RO profiles analysed ( 2000 events) for any latitude. For high latitudes the described features are not so sharp as for equatorial zones; but the tropopause points described here showed to be still detectable.

They are capable of retrieving about 2000 of GNSS-RO events/day. The satellites have onboard receivers with a high gain antenna and open-loop tracking channels [23]. The two METOP/ESA satellites A \& B were launched in 2006 and 2012 [30]. They collect more than 1000 events/day and are equipped with receivers capable to track the GNSS signal in open loop model [30] at a very high acquisition rate $(1000 \mathrm{~Hz})$. The two METOP satellites currently catch more than 1000 occultations/day.

In Table 2 are summarized the results of validation. Both the parameters $H_{\text {ave }}$ and $H_{\max }$ represent quite well the LRT (see yellow boxes of the tables). The agrement is particularly outstanding with LRT computed with RAOB (hLRTRAOB) which is well within the vertical resolution of GNSS-RO! The agreement with $H_{\max }$ seems slightly preferable but its scatter (see the II frame of Table 2) is meaningful higher. On the other hand $H_{0}$ is closer to the Cold Point Tropopause (CPT. $h_{C P T}$ and $h_{C P T-R A O B}$ ) and to the Radio Tropopause (RT, hRT). Also in this case the agreement with RAOB data is preferable. The main drawback is represented by the really high values of the scatter which could make unwise replace the CPT points with $H_{0}$. The validation of the RT [25] has been an added value of our analysis. The results shown confirm in an indirect way a good agreement of RT with CPT as claimed by the authors [25]. The average residuals between $H_{0}$ and $h_{\mathrm{RT}}$ are indeed very close to those with $h_{C P T}$. The scatter of $h_{R T}$ (not shown in Table 2), against $h_{C P T}$ and $h_{C P T-R A O B}$ is in turn of about 0.75 and $1.05 \mathrm{~km}$. 
Table 2. The tables summarize the result of validation performed. The first frame reports the average differences (given in $\mathrm{km}$ ) of the tropopause heights computed with our gauges against those given by the current standard methods. The II reports the same kind of comparison showing the scatter of the differences.

\begin{tabular}{cccccc}
\hline$\overline{(H-h)}(\mathrm{km})$ & $h_{C P T}$ & $h_{C P T-R A O B}$ & $h_{L R T}$ & $h_{L R T-R A O B}$ & $h_{R T}$ \\
\hline$H_{\text {ave }}$ & -0.990 & -1.275 & -0.275 & -0.147 & -1.122 \\
$H_{\max }$ & -0.918 & -1.224 & -0.235 & -0.143 & -1.070 \\
$H_{0}$ & 0.711 & 0.365 & 1.654 & 1.726 & 0.677 \\
$H_{\min }$ & 2.848 & 2.535 & 3.643 & 3.668 & 2.659 \\
\hline$\sigma(H-h)(\mathrm{km})$ & $h_{C P T}$ & $h_{C P T-R A O B}$ & $h_{L R T}$ & $h_{L R T-R A O B}$ & $h_{R T}$ \\
\hline$H_{\text {ave }}$ & 1.565 & 1.813 & 0.851 & 0.858 & 1.915 \\
$H_{\max }$ & 1.601 & 1.874 & 0.994 & 1.087 & 1.970 \\
$H_{0}$ & 1.759 & 1.773 & 1.984 & 2.091 & 1.963 \\
$H_{\min }$ & 3.370 & 3.178 & 3.858 & 3.869 & 3.135 \\
\hline
\end{tabular}

\section{Mapping Function}

The GNSS signal arrives to the receiver from a direction that forms an arbitrary angle with the zenith direction. Thus the most convenient way to model the TD is to express it as the product of the ZTD and a Mapping Function (hereafter MF). The MF is essentially a slant factor which provides the number of air masses crossed by the signal through the atmosphere as a function of the elevation angle $E . M F=1$ for the zenith direction; while $\mathrm{MF}=1 / \operatorname{Sin}(E)$ for other directions, assuming the layers of the atmosphere flat. But the atmosphere layers are not flat! Thus it was proposed in [31] [32] to express the MF in terms of a nested function with the following fashion:

$$
m(E)=\frac{1}{\sin (E)+\frac{a}{\sin (E)+\frac{b}{\sin (E)+\frac{c}{\sin (E)+\cdots}}}}
$$

The coefficients involved in Equation (3) were initially retrieved with RAOB with coefficients as function of some atmospheric parameters such as latitude, the Day Of the Year (DOY) and heights [33].

In the last years it was proposed to use directly the values of pressure, humidity and temperature provided by climatological (the Global Mapping Function: GMF) and/or Numerical Weather Prediction (the Vienna Mapping Function: VMF_1) models as in [34] [35] to estimate the values of the parameters. Thus the goal of our work was to re-estimate the NMF coefficients by using the huge amount of data coming from GNSS-RO space missions instead of RAOB and/or model profiles. In particular, we have used about 1,500,000 events since 2000, exploiting SAC-C [36], CHAMP [37] and COSMIC [23] data. The way how the MF is computed by applying ray-tracing technique is described in [33] [38]. Thus we have repeated exactly what it was done in [33] [38]. The coefficients of our MTMF were computed and organized in terms of Spherical Harmonics (SH) 
as already proposed in [34].

$$
\begin{aligned}
& a(\varphi, \lambda, t)=\sum_{n=0}^{n=?} \sum_{m=0}^{n} P_{n m} \sin (\varphi) \cdot\left(C(t)_{n m} \cos (m \lambda)+S(t)_{n m} \sin (m \lambda)\right) \\
& b(\varphi, \lambda, t)=\cdots \\
& c(\varphi, \lambda, t)=\cdots
\end{aligned}
$$

In our case the big number of GNSS-RO observations collected up to now have allowed us to extend the computation of harmonic up to the 18th degree instead of 8th as in [34]. We skip of course the discussion of the advantage achieved in using this new MF [38] for the estimates of station coordinates and ZTD of GNSS stations. We would rather outline that the MTMF computed in such fashion could be exploited as a climate fingerprint as well. If you look at Figure 3 a meaningful different seasonal behaviour of MF can be noticed. We like to emphasize that the intriguing opportunity to use the MTMF as a climate fingerprint is given by the almost uniform and global coverage of GNSS-RO observations all over the world which cannot be guaranteed, on the contrary, by RAOB observations. Essentially MF represents the number of air masses crossed by the GNSS signal. The air masses crossed depends both by the atmospheric geometry and by the optical thickness (essentially the density and chemical composition of the atmosphere!). So the evolution in time of MTMF (not only seasonal) could give us information about the atmosphere climate change.
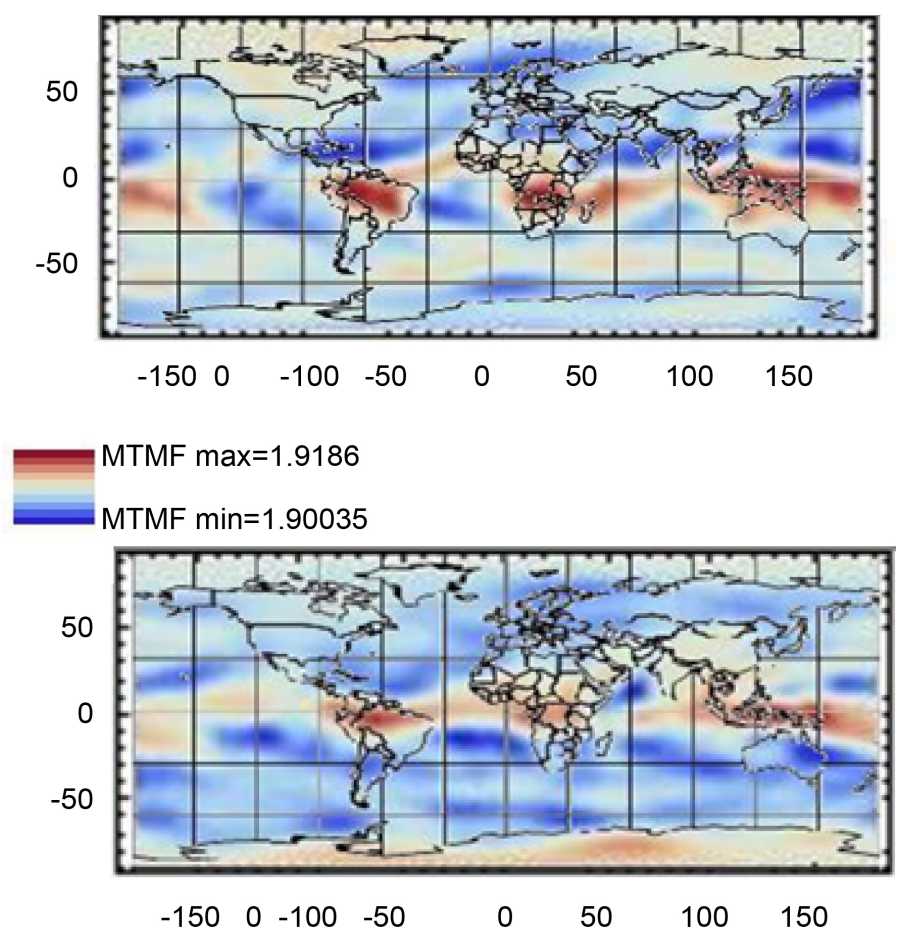

Figure 3. In figures the value of the MTMF on global scale is shown. The first frame concerns the first 45 day of the year, while the II concerns the period Mid May, June (two seasonal opposite periods). The MTMF values on world plot have been computed for an elevation angle $\mathrm{E}=30^{\circ}$. 


\section{Conclusion}

It is currently well known the relevance of the tropopause as a fingerprint to study atmospheric Global Change. The huge availability of GNSS RO data thanks to missions like COSMIC or METOP, have made its measurements on global scale easier and more precise. Furthermore it has been realized that atmospheric profiles other than temperature ones, e.g. refractivity or BA, could make still easier and more precise the measurement of tropopause height. In the present paper we have proposed indeed a new method to determine the tropopause. The method we have proposed fits the BA profiles assuming Hf as refractivity dry model. The model was built [28] assuming as constant the LRT. Thus the layers in which tropopause is contained (i.e. where LRT is changing), the residuals have an anomalous trend. The "colored" residuals through these layers form indeed ripples that we have exploited just to determine the relevant parameters of the tropopause. In particular from the residuals between the computed Hf dry model and the observed BA we have extracted 4 possible parameters: $H_{\text {ave }}, H_{\text {max }} H_{0}$ and $H_{\text {min }}$. The first 2 parameters have revealed to be very close to the LRT; while $H_{0}$ is closer to the CPT. The activity developed have also provided, as by product, the validation of the Radio Tropopause [25]. Our work focused on the design and development of a method for determining the tropopause by using level 1 data coming from GNSS-RO observations. In the next step we will apply our new approach for climate investigations. In particular we plan to replay exactly the analysis performed in [24] but for a longer period of 8 years at least (i.e. while the COSMIC/METOP and/or other source of data will be available). Finally we have proposed to use the MTMF built by GNSS RO data, as another possible climate fingerprint. Also in this case we plan to detect secular variations of the behaviour of the MTMF which could be correlated in some way to climatic change occurring on Earth.

\section{References}

[1] Houghton, J.T. (1995) Detection of Climate Change and Attribution of Causes. Climate Change. In: Houghton, J.T., MeiraFilho, L.G., Callander, B.A., Harris, N., Kattenbergand, A. and Maskell, K., Eds., the Science of Climate Change, Cambridge University Press, Cambridge, 407-444.

[2] Stocker, T.M. and Qin, D. (2013) Fifth Assessment Report of the Intergovernmental Panel on Climate Change (IPCC).

[3] Barnett, T.P., Pierce, D.W. and Schnur, R. (2001) Detection of Anthropogenic Climate Change in the World's Oceans. Science, 292, 270-274.

https://doi.org/10.1126/science.1058304

[4] Vinnikov, K.Y., Robock, A. and Stouffer, R.J. (1999) Global Warming and Northern Hemisphere Sea Ice Extent. Science, 286, 1934-1937.

https://doi.org/10.1126/science.286.5446.1934

[5] Drost, F., Karoly, D. and Braganza, K. (2012) Communicating Global Climate Change Using Simple Indices: An Update. Climate Dynamics, 39, 989-999. https://doi.org/10.1007/s00382-011-1227-6

[6] Karl, T.R., Knight, R.W. and Plummer, N. (1995) Trends in High-172 Observed Climate Variability and Change Frequency Climate Variability in the Twentieth 
Century. Nature, 377, 217-220. https://doi.org/10.1038/377217a0

[7] Hansen, J., Sato, M., Lacis, A., Rueby, R., Tegen, I. and Matthews, E. (1998) Climate Forcing in the Industrial Era. Proceedings of the National Academy of Sciences, 95, 12753-12758. https://doi.org/10.1073/pnas.95.22.12753

[8] Santer, B.D., Sausen, R., Wigley, T.M.L., et al. (2003) Behavior of Tropopause Height and Atmospheric Temperature in Models, Reanalyses and Observations: Decadal Changes. Journal of Geophysical Research, 108, ACL1-1-ACL1-22. https://doi.org/10.1029/2002JD002258

[9] Sausen, R. and Santer, B.D. (2003) Use of Changes in Tropopause Height to Detect Human Influences on Climate. Meteorologische Zeitschrift, 12, 131-136. https://doi.org/10.1127/0941-2948/2003/0012-0131

[10] Seidel, D.J., Ross, R.J., Angell, J.K., et al. (2001) Climatological Characteristics of the Tropical Tropopause as Revealed by Radiosondes. Journal of Geophysical Research, 106, 7857-7878. https://doi.org/10.1029/2000JD900837

[11] Hoinka, C. (1997) The Tropopause: Discovery, Definition and Demarcation. $\mathrm{Me}$ teorologische Zeitschrift, 6, 281-303.

[12] Schiller, C., Grooss, J.U., Konopka, P., Plager, F., Silva dos Santos, F.H. and Spelten, N. (2009) Hydration and Dehydration at the Tropical Tropopause. Atmospheric Chemistry and Physics, 9, 9647-9660. https://doi.org/10.5194/acp-9-9647-2009

[13] Ramaswamy, V., et al. (2001) Stratospheric Temperature Trends: Observations and Model Simulations. Reviews of Geophysics, 39, 71-122.

https://doi.org/10.1029/1999rg000065

[14] Randel, W.J., Wu, F. and Gaffen, D.J. (2000) Interannnual Variability of the Tropical Tropopause Derived from Radiosonde Data and NCEP Reanalyses. Journal of Geophysical Research: Atmospheres, 105, 15509-15523. https://doi.org/10.1029/2000JD900155

[15] Mehta, S.K., VenkatRatnam, M. and Krishna Murthy, B.V. (2011) Multiple Tropopauses in the Tropics: A Cold Point Approach. Journal of Geophysical Research: Atmospheres, 116, D20105. https://doi.org/10.1029/2011JD016637

[16] Santer, B.D., et al. (2003) Contributions of Anthropogenic and Natural Forcing to Recent Tropopause Height Changes. Science, 301, 479-483. https://doi.org/10.1126/science.1084123

[17] Schmidt, G.A. (2009) Spurious Correlations between Recent Warming and Indices of Local Economic Activity. International Journal of Climatology, 29, 2041-2048. https://doi.org/10.1002/joc.1831

[18] Randel, W.J. and Wu, F. (2005) Kelvin Wave Variability near the Equatorial Tropopause Observed in GNSS Radio Occultation Measurements. Journal of Geophysical Research: Atmospheres, 110, D03102. https://doi.org/10.1029/2004JD005006

[19] Wang, J.S., Seidel, D.J. and Free, M. (2012) How Well Do We Know Recent Climate Trends at the Tropical Tropopause? Journal of Geophysical Research: Atmospheres, 117, D09118. https://doi.org/10.1029/2012jd017444

[20] Randel, W.J., Wu, F., Vömel, H., Nedoluha, G.E. and Forster, P. (2006) Decreases in Stratospheric Water Vapor after 2001: Links to Changes in the Tropical Tropopause and the Brewer-Dobson Circulation. Journal of Geophysical Research: Atmospheres, 111, D12312. https://doi.org/10.1029/2005jd006744

[21] Randel, W.J. and Jensen, E.J. (2013) Physical Processes in the Tropical Tropopause Layer and Their Roles in a Changing Climate. Nature Geoscience, 6, 169-176. https://doi.org/10.1038/ngeo1733

[22] Melbourne, W., et al. (1994) The Application of Space Borne GNSS to Atmospheric 
Limb Sounding and Global Change Monitoring. JPL Publication, 147, 1-26.

[23] Anthes, R.A., Bernhardt, P.A., Chen, Y., Cucurull, L., et al. (2008) The COSMIC/ FORMOSAT-3 Mission: Early Results. Bulletin of the American Meteorological Society, 89, 313-333. https://doi.org/10.1175/bams-89-3-313

[24] Chu, B. and Chao, W. (2011) Global Tropopause Height Variabilities Derived from FormoSat-3/COSMIC GNSS Occultation Data. 5th FORMOSAT-3/COSMIC Data Users Workshop \& ICGNSSRO 2011, April.

[25] Rao, N.D., Venkat Ratnam, M., et al. (2007) Identification of Tropopause Using Bending Angle Profile from GNSS Radio Occultation (RO): A Radio Tropopause. Geophysical Research Letters, 34, L15809.

[26] Vespe, F. and Persia, T. (2006) Derivation of the Water Vapor Content from the GNSS Radio Occultations Observations. Journal of Atmospheric and Oceanic Technology, 23, 936-943. https://doi.org/10.1175/JTECH1891.1

[27] Vespe, F., Wickert, J., Benedetto, C. and Pacione, R. (2005) Derivation of the Water Vapor Content from the GNSS Radio Occultation Observations. In: Reigber, C., et al., Eds., Earth Observation with CHAMP. Results from Three Years in Orbit, Springer, Berlin, 537-543. https://doi.org/10.1007/3-540-26800-6_85

[28] Hopfield, H.S. (1969) Two-Quartic Tropospheric Refractivity Profile for Correcting Satellite Data. Journal of Geophysical Research, 74, 4487-4499.

https://doi.org/10.1029/JC074i018p04487

[29] Vespe, F. (2016) Retrieval of Atmosphere Humidity Profiles from GNSS Radio Occultation Observations. Proceedings of the 67 th IAC Conference, Guadalajara (Mex).

[30] von Engeln, A., et al. (2009) GRAS Radio Occultation Onboard of Metop. Proceedings of the 2nd International Colloquium-Scientific and Fundamental Aspects of the Galileo Programme, Padua, 14-16 October 2009.

[31] Marini, J.W. (1972) Correction of Satellite Tracking Data for an Arbitrary Tropospheric Profile. Radio Science, 7, 223-231. https://doi.org/10.1029/RS007i002p00223

[32] Marini, J.W. and Murray, C.W. (1973) Correction of Laser Range Tracking Data for Atmospheric Refraction at Elevations above 10 Degrees. NASA Tech. Memo., NASA-TM-X-70555, $60 \mathrm{p}$.

[33] Niell, A.E. (1996) Global Mapping Functions for the Atmosphere Delay at Radio Wavelengths. Journal of Geophysical Research: Solid Earth, 100, 3227-3246. https://doi.org/10.1029/95JB03048

[34] Boehm, J., Niell. A., Tregoning, P. and Schuh, H. (2006) Global Mapping Function (GMF). A New Empirical Mapping Function Based on Numerical Weather Model Data. Geophysical Research Letters, 33, L07304. https://doi.org/10.1029/2005GL025546

[35] Boehm, J., Kouba, J. and Schuh, H. (2009) Forecast Vienna Mapping Functions for Real-Time Analysis of Space Geodetic Observations. Journal of Geodesy, 83, 397401. https://doi.org/10.1007/s00190-008-0216-y

[36] Alonso, C. and Hoffmann, C. (2000) SAC-C Mission. http://www.conae.gov.ar/satelites/sac-c/SAC-CPUBLI200208.pdf

[37] Wickert, J., et al. (2001) Atmosphere Sounding by GNSS Radio Occultation: First Results from CHAMP. Geophysical Research Letters, 28, 3263-3266. https://doi.org/10.1029/2001GL013117

[38] Vespe, F., Benedetto, C., Rosciano, E. and Vizziello, G. (2003) A New Mapping Function Recovered from Atmospheric Profiles Retrieved by GNSS Radio Occultation Data. Proceedings of the V GALILEO Sci. Colloquium, Prague. 
Submit or recommend next manuscript to SCIRP and we will provide best service for you:

Accepting pre-submission inquiries through Email, Facebook, LinkedIn, Twitter, etc. A wide selection of journals (inclusive of 9 subjects, more than 200 journals)

Providing 24-hour high-quality service

User-friendly online submission system

Fair and swift peer-review system

Efficient typesetting and proofreading procedure

Display of the result of downloads and visits, as well as the number of cited articles Maximum dissemination of your research work

Submit your manuscript at: http://papersubmission.scirp.org/

Or contact acs@scirp.org 